\title{
The Effect of Varying Water-to-Powder Ratios on the Microhardness and Microstructure of Mineral Trioxide Aggregate
}

\author{
R. Den ${ }^{1, *}$ \\ R. Dharmastiti ${ }^{1}$ \\ Nuryono $^{2}$ \\ L. Yuliatun ${ }^{2}$ \\ Widjijono $^{3}$
}

${ }^{1}$ Department of Mechanical and Industrial Universitas

Yogyakarta, Engineering,

2Department of Chemistry, Universitas Gadjah Mada, Yogyakarta, Indonesia. 3Department of Dental Biomaterial Science, Universitas Gadjah Mada, Yogyakarta, Indonesia

Email:

*denrethy@gmail.com

\section{Keywords}

Microhardness, Microstructure, Mineral trioxide aggregate, Water-to-powder ratio.

\begin{abstract}
The composition of water and powder in a mixture is one of the common problems in application as clinicians typically estimate the ratio chairside. The purpose of this study was to investigate the effect of varying water-topowder ratios on the microhardness and microstructure of mineral trioxide aggregate (MTA). ROOTDENT MTA was investigated. One gram of cement was mixed with $0.28,0.33$, and 0.40 grams of distilled water and was stored for 1, 7, and 28 days in the water. Samples were subjected to x-ray diffraction (XRD), scanning electron microscopy (SEM), and microhardness tests. Tricalcium silicate, dicalcium silicate, zirconium dioxide, calcium carbonate, and calcium hydroxide were detected by XRD. SEM showed the presence of amorphous, porous capillary channel and capillary structure on the surface of the specimens. The SEM image for each water-to-powder ratio of the surface of the material was indistinguishable from the other. The highest microhardness was exhibited by the MTA specimen with the 0.33 water-to-powder ratio submerged in the water for 28 days.
\end{abstract}




\section{Introduction}

Mineral trioxide aggregate (MTA) is described as an endodontic cement with good biocompatibility and sealing property in clinical application (M. Torabinejad and N. Chivian, 1999). MTA is widely used as rootend filling material and perforation repair. Two types of MTA have been introduced: grey MTA and white MTA. White MTA is derived from grey MTA by removing iron from the MTA composition. MTA consists primarily of tricalcium silicate, dicalcium silicate, tricalcium aluminate, and bismuth oxide (S. Asgary et al, 2008), (J. Camilleri et al, 2005).

The properties of hardened MTA depend on several factors, including particle size, powder-to-liquid ratio, environmental temperature, and the presence of air in the mixture (M. Torabinejad et al, 1993). Some previous studies reported that $\mathrm{pH}$ also influenced the surface hardness of the cement (M. S. Namazikhah et al, 2008), ( M. A. Saghiri et al, 2009). In clinical application, varying water-to-powder (WP) ratios are one of the common factors impacting the properties of MTA since clinicians usually mix water and powder in certain ratios chairside (F. B. Basturk et al, 2013). Porosity and compressive strength are also affected by the amount of water in the mixture .(F. B. Basturk et al, 2015), (M. Fridland and R. Rosado, 2003). However, some properties, such as setting expansion, are not influenced by WP ratio (M. Hawley et al, 2010). This research was also driven by the hope to reduce MTA importation by domestically producing MTA. Hence, it is deemed important to perform characterization of the properties of commercial MTA to produce MTA with locally derived materials.

The purpose of this research was to investigate the effect of varying water-topowder ratios on the microhardness and microstructure of mineral trioxide aggregate (MTA).

\section{Materials and Methods}

\subsection{Materials}

ROOTDENT (compounded by 'TehnoDent' Co. Ltd, Belgorod region, Russia) was selected for this study. The composition includes calcium oxide, silicon oxide, aluminum oxide, and zirconia oxide.

\subsection{Samples Preparation}

The specimens were separated into 3 groups. One gram of MTA powder of each group was mixed with $0.28,0.33$, or 0.40 gram of distilled water, respectively, and submerged in the water for 1, 7, and 28 days, respectively. A cylindrical aluminum mold (internal diameter of $4 \mathrm{~mm}$ and depth of $8 \mathrm{~mm}$ ) was prepared by lubricating it with a mold release agent (Sika Separol, Switzerland). MTA and water were hand-mixed with a spatula on a glass plate. The slurry was later transferred to the cylindrical aluminum mold. The slurry was compacted into each hold of the mold by a dental plugger. The mold was stored for 24 hours at room temperature $\left(28 \pm 3^{\circ} \mathrm{C}\right)$ and room humidity $(60-80 \%)$. The samples were removed from the mold and were submerged in the water (humidity of $100 \%$ ) at room temperature. The specimens were taken out from the water after 1, 7, or 28 days and left to dry at room temperature and humidity.

\subsection{X-ray Diffraction}

Samples of different WP ratios, presented in powder, were subjected to phase analyses by X-ray diffraction (XRD). XRD was performed by MAXima_X XRD-7000 powder diffractometer (SHIMADZU, Kyoto, Japan) at an angle of rotation of between $5^{\circ}$ and $45^{\circ}$ with an angle increment of $0.05^{\circ}$ and a scanning speed of $2^{\circ} / \mathrm{min}$. Identification was later derived from the phase analysis.

\subsection{Scanning Electron Microscopy}

Zeiss Evo MA10 SEM (Carl Zeiss, Oberkochen, Germany) was used to investigate the microstructure of the cement. 
Three specimens of different WP ratios were grinded, polished, and coated with carbon. Then, the specimens were observed under a scanning electron microscope, and the data were recorded.

\subsection{Hardness}

The specimens were submitted to hardness tests. The specimens were grinded with 800-grit silicon carbide paper, then 2000grit. A black drawing pen (SNOWMAN 700, Japan) was used for amplifying the thin layer color on the sample surface to aid the observation of the impression left by an indenter. The samples were then loaded onto a Vickers micro hardness tester machine (Buehler, Chicago, USA) with a diamond indenter. A load of $100 \mathrm{gf}$ was applied on the surface of the specimens for 10 seconds using the indenter, then released. The two diagonals of the impression were measured and the Vickers hardness number calculated using Eq. (1):

$$
H V=\frac{1854.4 P}{d^{2}}
$$

where $H V$ is Vickers hardness number $\left(K g / \mathrm{mm}^{2}\right), d$ is the mean diagonal (mm), and $P$ is the applied load.

\section{Results and Discussion}

The results of X-ray diffraction (XRD) of the hydrated MTA specimens at $0.28,0.33$, and $0.40 \mathrm{WP}$ ratios which were submerged 28 days in the water are shown in Figure 1. The phases identified are in agreement with previous studies (F. B. Basturk et al, 2018), (S. Chen et al, 2018). All samples of three different ratios showed peak intensities at similar diffraction angles. The phases identification of MTA at the 0.28 WP ratio included tricalcium silicate $\left(\mathrm{Ca}_{3} \mathrm{SiO}_{5}\right)$ with a peak at the angle of $29.39^{\circ}$, dicalcium silicate $\left(\mathrm{Ca}_{2} \mathrm{SiO}_{4}\right)$ with a peak at the angle of $43.07^{\circ}$, zirconium dioxide $\left(\mathrm{ZrO}_{2}\right)$ with two peaks at the angles of $23.12^{\circ}$ and $31.34^{\circ}$, calcium carbonate $\left(\mathrm{CaCO}_{3}\right)$ with a peak at the angle of $39.46^{\circ}$, and calcium hydroxide $\left(\mathrm{Ca}(\mathrm{OH})_{2}\right)$ with a peak at the angle of $17.85^{\circ}$.

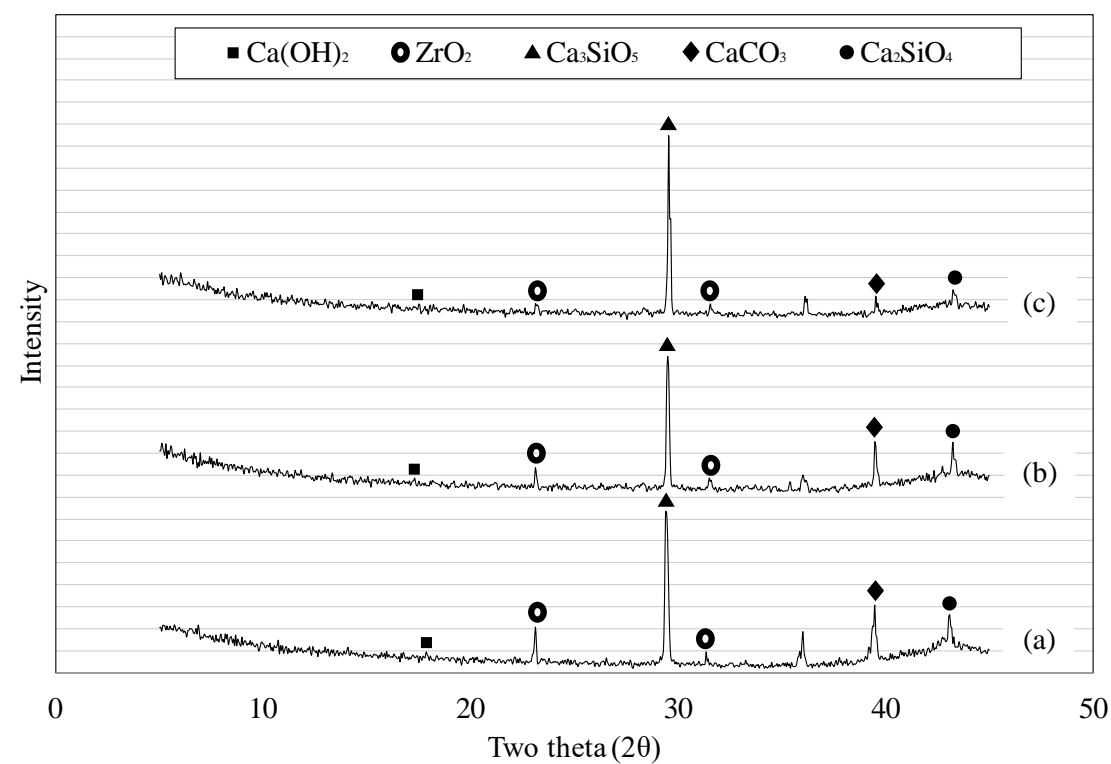

Figure 1. X-ray diffractogram of hydrated MTA submerged in the water for 28 days at (a) the $0.28 \mathrm{WP}$ ratio, (b) the $0.33 \mathrm{WP}$ ratio, and (c) the $0.40 \mathrm{WP}$ ratio 


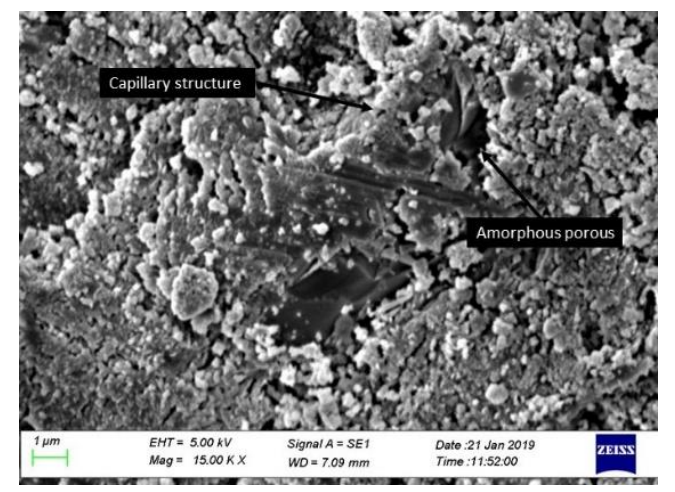

Figure 2. Scanning electron microscopy (SEM) of hydrated MTA at the 0.28 WP ratio submerged 28 days in the water

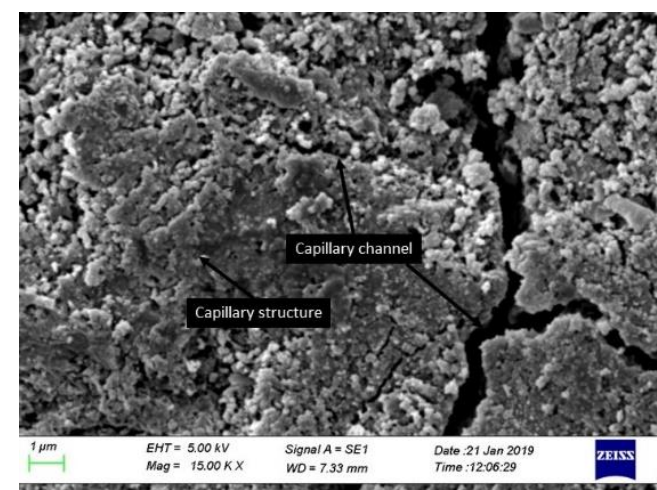

Figure 3. Scanning electron microscopy (SEM) of hydrated MTA at the 0.33 WP ratio submerged 28 days in the water

The phases identification of MTA at the $0.33 \mathrm{WP}$ ratio included tricalcium silicate $\left(\mathrm{Ca}_{3} \mathrm{SiO}_{5}\right)$ with a peak at the angle of $29.49^{\circ}$, dicalcium silicate $\left(\mathrm{Ca}_{2} \mathrm{SiO}_{4}\right)$ with a peak at the angle of $43.22^{\circ}$, zirconium dioxide $\left(\mathrm{ZrO}_{2}\right)$ with two peaks at the angles of $23.12^{\circ}$ and $31.49^{\circ}$, calcium carbonate $\left(\mathrm{CaCO}_{3}\right)$ with a peak at the angle of $39.46^{\circ}$, and calcium hydroxide $\left(\mathrm{Ca}(\mathrm{OH})_{2}\right)$ with a peak at the angle of $17.30^{\circ}$. The phases identification of MTA at the $0.40 \mathrm{WP}$ ratio included tricalcium silicate $\left(\mathrm{Ca}_{3} \mathrm{SiO}_{5}\right)$ with a peak at the angle of $29.54^{\circ}$, dicalcium silicate $\left(\mathrm{Ca}_{2} \mathrm{SiO}_{4}\right)$ with a peak at the angle of $43.22^{\circ}$, zirconium dioxide $\left(\mathrm{ZrO}_{2}\right)$ with two peaks at the angles of $23.12^{\circ}$ and $31.54^{\circ}$, calcium carbonate $\left(\mathrm{CaCO}_{3}\right)$ with a peak at the angle of $39.51^{\circ}$, and calcium hydroxide $\left(\mathrm{Ca}(\mathrm{OH})_{2}\right)$ with a peak at the angle of $17.50^{\circ}$.

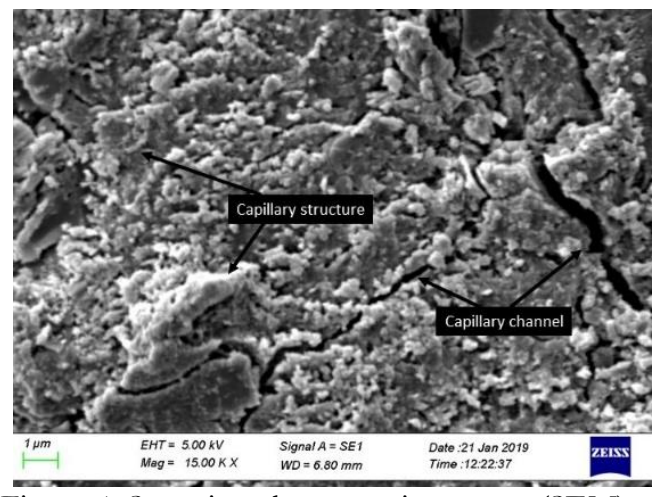

Figure 4. Scanning electron microscope (SEM) of hydrated MTA with $0.40 \mathrm{WP}$ ratio submerged 28 days in the water.

The scanning electron microscopy (SEM) images of the hydrated MTA surface submerged 28 days in the water at the 0.28 , 0.33 , and $0.44 \mathrm{WP}$ ratios are shown in Figure 2-4. The SEM images for different WP ratios show the presence of amorphous, porous capillary channel and capillary structure on the surfaces of the specimens.

The results of the microhardness tests are presented in Figure 5. The MTA microhardness mean and standard deviation at the 0.33 WP ratio were higher $(91.00 \pm 13.12)$ than those at the $0.28 \mathrm{WP}$ ratio $(64.88 \pm 7.91)$, while those at the 0.40 WP ratio were found to be the lowest $(42.87 \pm 10.10)$. The mean and standard deviation of microhardness of the MTA specimen with $0.33 \mathrm{WP}$ ratio submerged in the water for 1,7 , and 28 days had no statistically significant differences. However, the mean value of microhardness of that with the $0.33 \mathrm{WP}$ ratio and submerged in the water for 28 days was the highest.

\section{Discussions}

$\mathrm{X}$-ray diffraction analysis is a very useful tool for assessment of crystalline 
materials. It has been used for the phase composition, chemical analysis, and
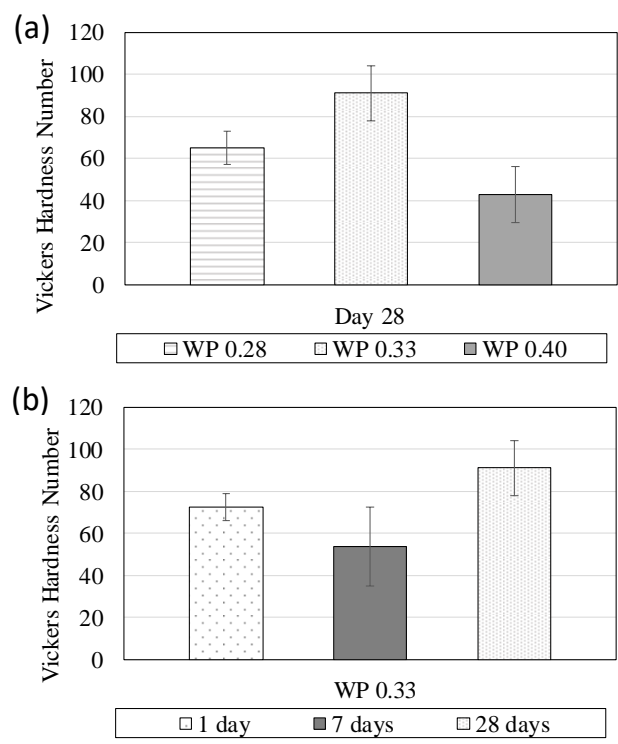

Figure 5. Means and standard deviations of microhardness of MTA (a) WP 0.28 , WP 0.33 , and WP 0.40 after Day 28 in the water; (b) Day 1,

Day 7, and Day 28 in the water of WP 0.33 .

hydration characteristization of mineral trioxide aggregate(F. B. Basturk et al, 2018). Zirconium dioxide was not involved in hydration process (S. Chen et al, 2018) and might used as a radiopacifying material for the cement(A. Cutajar et al, 2011). Tricalcium silicate took 28 days to fully hydrate, while dicalcium silicate took longer ( $\mathrm{S}$. Chen et al, 2018). The hydration reaction of MTA produced calcium silicate hydrate and calcium hydroxid (J. Camilleri, 2007). However, since calcium silicate hydrate was amorphous, its presence was not detected by XRD(L. M. Formosa et al, 2013).

The porosity of dental cement is usually caused by mixing cement and liquid. The porosity is due to the incorporation of microscopic air bubbles during the mixing operation (M. Torabinejad et al, 1995). A study reported that the presence of an amorphous, porous capillary structure was also one of the important factors causing porosity in MTA (M. Fridland and R. Rosado, 2003). However, in this research, these SEM images failed to show any difference between the $0.28,0.33$, and $0.44 \mathrm{WP}$ ratios.

The microhardness of the cement depends on particle size, water-to-powder ratio, temperature, humidity, and air entrapment (M. Torabinejad et al, 1995). In this research, the storage temperature of set MTA affected the microhardness, for example, room temperature or higher could provide better hardness. Porosity had a negative corrolation with surface hardness, or in other words, as the porosity increased, the hardness of the cement decreased ( M. A. Saghiri et al, 2009). The porosity increased with the amount of water (M. A. Saghiri et al, 2009). This indicates that higher WP ratios resulted in lower surface hardness. However, the lacking amount of water in the mixture produced lower hardness since water is important in the setting reaction of MTA. The hardness of the cement is influenced by other fundamental properties such as yield strength, tensile strength, and modulus of elasticity (M. Fridland and R. Rosado, 2005). In this research, the compressive strength of MTA increased over time in the water and was found to be the highest in 28 days of submersion (D. P. Bentz, 2007). This confirms that the microhardness of MTA increases over time in the water as the MTA continued to set until 28 days. MTA with the 0.33 WP ratio which was submerged for 28 days in the water provided sufficient hydration for the microhardness of MTA.

\section{Conclusion}

Tricalcium silicate, dicalcium silicate, zirconium dioxide, calcium carbonate, and calcium hydroxide were detected by XRD. SEM showed the presence of amorphous, porous capillary channel and capillary structure on the surface of the specimens. SEM images showed no differences between the $0.28,0.33$, and $0.40 \mathrm{WP}$ ratios. The highest microhardness was shown by the MTA specimen with the $0.33 \mathrm{WP}$ ratio that was submerged in the water for 28 days. 


\section{References}

A. Cutajar, B. Mallia, S. Abela and J. Camilleri, "Replacement of radiopacifier in mineral trioxide aggregate; Characterization and determination of physical properties," Dental Materials, vol. 27, no. 9, pp. 879-891, 92011.

D. P. Bentz, "Cement hydration: Building bridges and dams at the microstructure level," Materials and Structures/Materiaux et Constructions, vol. 40, no. 4, pp. 397-404, 52007.

F. B. Basturk, M. H. Nekoofar, M. Gunday and P. M. Dummer, "Effect of varying water-to-powder ratios and ultrasonic placement on the compressive strength of mineral trioxide aggregate," Journal of Endodontics, vol. 41, no. 4, pp. 531 534, 2015.

F. B. Basturk, M. H. Nekoofar, M. Günday and P. M. Dummer, "The effect of various mixing and placement techniques on the compressive strength of mineral trioxide aggregate," Journal of Endodontics, vol. 39, no. 1, pp. 111114, 12013

F. B. Basturk, M. H. Nekoofar, M. Gunday and P. M. Dummer, "X-ray diffraction analysis of MTA mixed and placed with various techniques," Clinical Oral Investigations, vol. 22 , no. 4 , pp. 1675 1680, 152018.

I. Islam, H. Kheng Chng and A. U. Jin Yap, "Comparison of the physical and mechanical properties of MTA and portland cement," Journal of Endodontics, vol. 32, no. 3, pp. 193197, 32006.

J. Camilleri, "Hydration mechanisms of mineral trioxide aggregate," International Endodontic Journal, vol. 40, no. 6, pp. 462-470, 62007.

J. Camilleri, F. E. Montesin, K. Brady, R. Sweeney, R. V. Curtis and T. R. Ford, "The constitution of mineral trioxide aggregate," Dental Materials, vol. 21, no. 4, pp. 297-303, 42005.

L. M. Formosa, B. Mallia and J. Camilleri, "Mineral trioxide aggregate with anti- washout gel-Properties and microstructure," Dental Materials, vol. 29, no. 3, pp. 294-306, 32013.

M. A. Saghiri, M. Lotfi, A. M. Saghiri, S. Vosoughhosseini, M. Aeinehchi dan B. Ranjkesh, "Scanning Electron Micrograph and Surface Hardness of Mineral Trioxide Aggregate in the Presence of Alkaline $\mathrm{pH}$," Journal of Endodontics, vol. 35, no. 5, pp. 706710, 52009.

M. A. Saghiri, M. Lotfi, A. M. Saghiri, S. Vosoughhosseini, M. Aeinehchi and B. Ranjkesh, "Scanning Electron Micrograph and Surface Hardness of Mineral Trioxide Aggregate in the Presence of Alkaline $\mathrm{pH}$," Journal of Endodontics, vol. 35, no. 5, pp. 706710, 52009.

M. Fridland and R. Rosado, "Mineral trioxide aggregate (MTA) solubility and porosity with different water-topowder ratios," Journal of Endodontics, vol. 29, no. 12, pp. 814817, 2003.

M. Fridland and R. Rosado, "MTA solubility: A long term study," Journal of Endodontics, vol. 31, no. 5, pp. 376379, 2005.

M. Hawley, T. D. Webb and G. G. Goodell, "Effect of varying water-to-powder ratios on the setting expansion of white and gray mineral trioxide aggregate," Journal of Endodontics, vol. 36, no. 8, pp. 1377-1379, 2010.

M. S. Namazikhah, M. H. Nekoofar, M. S. Sheykhrezae, S. Salariyeh, S. J. Hayes, S. T. Bryant, M. M. Mohammadi dan P. M. Dummer, "The effect of $\mathrm{pH}$ on surface hardness and microstructure of mineral trioxide aggregate," International Endodontic Journal, vol. 41, no. 2, pp. 108-116, 22008.

M. Torabinejad and N. Chivian, "Clinical Applications of Mineral Trioxide Aggregate," 1999.

M. Torabinejad, C. U. Hong, F. Mcdonald and T. R. Pitt Ford, "Physical and Chemical 
Properties of a New Root-End Filling Material," 1995.

M. Torabinejad, T. F. Watson and T. R. Pitt Ford, "Sealing Ability of a Mineral Trioxide Aggregate When Used As a Root End Filling Material," 1993.

S. Asgary, S. Shahabi, T. Jafarzadeh, S. Amini and S. Kheirieh, "The Properties of a New Endodontic Material," Journal of Endodontics, vol. 34, no. 8, pp. 990993, 82008.

S. Chen, L. Shi, J. Luo and H. Engqvist, "Novel Fast-Setting Mineral Trioxide Aggregate: Its Formulation, ChemicalPhysical Properties, and Cytocompatibility," ACS Applied Materials and Interfaces, vol. 10, no. 24, pp. 20334-20341, 2062018. 